\title{
Correspondence
}

\section{The Royal College examination and award of qualification}

\section{DEAR SIRS}

I read with some disquiet the letter from Dr Mathew concerning the Royal College examination and award of qualification (Psychiatric Bulletin, 1991, 15, 699-700) and I would like to make the following comments.

Dr Mathew claims that in the study by Bhate (1990) overseas graduates take between five and eight years to pass the membership examination after they enter psychiatric practice. I would comment that this is not limited to overseas doctors and many nonoverseas doctors take this length of time to get the membership examination. He claims that this could result in unfortunate candidates being forced to leave without having any qualification to confirm the psychiatric training they had in the United Kingdom. I would comment that it is not necessary to have a degree to confirm the psychiatric training received as this would surely appear on a curriculum vitae and indeed referees from the United Kingdom may well be used when people return to their country of origin to seek further employment.

He comments that the Government's policy of creating staff grade posts is a good move and goes on to say that doctors are forced to opt out of psychiatry when they exhaust their examination attempts. But this is hardly the case as surely the staff grade appointment is one option for those who do not pass the membership and a career in psychiatry can be continued.

Although there is no further degree obtainable in psychiatry, as Dr Mathew notes, he suggests a rather convoluted plan of action to counteract this "deficiency". As a recently graduated member of the College and having taken the exams when the format of the examination was changing and been involved in the subsequent confusion, etc. surrounding the same, both on the part of examiners and candidates, I feel that his suggestions are at best unrealistic. Although a second degree (e.g. DPM) would undoubtedly be welcome by those who are, due to unfortunate circumstances, unable to complete the membership examination, Dr Mathew's method of implementation leaves one with a sense of confusion that it is difficult to dispel.

Finally, I totally disagree with his comment that more doctors would continue in psychiatry but should they be able to obtain a psychiatric qualification this would improve health care in general, and I note that Dr Mathew gives no reference and no evidence in support of such a claim.

\section{Meanwood Park Hospital} Leeds LS6 4QB

JANE O'DWYER

\section{DeAR SiRS}

Dr O'Dwyer disregarded the salient point in my letter, that the current immigration and membership examination regulations prevent some, mainly overseas doctors, from sitting for the membership examination on the maximum eligible number of occasions. She claimed that many non-overseas doctors take five to eight years to pass the membership examination after they enter psychiatric practice but does not support this statement with any reference or personal experience.

She concluded "that it is not necessary to have a degree to confirm one's psychiatric training which they have received as this would surely appear on a curriculum vitae and indeed references from the United Kingdom may well be used when people return to their country of origin to seek further employment". Her judgement on this seems fallacious, and she does not appear to understand how medical systems operate in third world countries. If one can be appointed to a suitable job on the basis of curriculum vitae alone I wonder why doctors bother to take the membership examination. Procuring a British degree in psychiatry is highly valued all over the world.

Also, although staff grade posts do not require any formal postgraduate qualification, in practice they are usually filled by doctors who have membership but been unable to procure a higher training post for personal reasons. The difficulty arises only when a doctor takes up staff psychiatrist post before passing the membership. She states that she was confused going through the new format of the examination. Fortunately, this has not been experienced by many of us who took the same examination which may explain why she found it so difficult to grasp the method of implementation suggested by me. She is welcome to suggest a better method of implementation.

The main aim of my letter was to bring to the attention of the Royal College of Psychiatrists the need to have an alternate form of qualification other than the membership examination, similar to the one awarded by most of the Royal Colleges in the United Kingdom (eg DA; DLO; DGM; DCH; DTM\&H; 
DRCOG etc). It is for the Examination Committee to decide how changes should be implemented.

University of Leicester

V. M. MATHEW

Leicester Royal Infirmary

Leicester LE2 $7 L X$

DeAR Sirs

Being an overseas trainee working on the overseas doctors training scheme, I fully support the points made by Dr Mathew (Psychiatric Bulletin, 1991, 15, 699-700). I feel that he has raised an important issue. It would indeed be impossible for all those overseas trainees who wish to take membership examination to make the full number of attempts for their Part I and Part II of the MRCPsych.

Being allowed to stay in the UK for only four years will certainly cause a lot of anxiety among those candidates who fail to pass within the first few attempts. The Dean and the Chief Examiner in their reply have pointed out that most of the overseas trainees do not want to take the MRCPsych examination which I think is not true. Given the chance to take the examination, most of the doctors will wish to get a high class British qualification. The suggestion of an alternative examination is very good and the College should consider it seriously.

The Dean and the Chief Examiner have also mentioned that it would involve a lot of expenditure to conduct such an examination. As far as the financial aspect is concerned, I think that the College can recover a handsome amount of money from the candidates in respect of fees. Introduction of the DPM or any equivalent qualification would especially be of benefit to those who are limited to a few years in the United Kingdom or who are unable to pass the MRCPsych examination.

The College may not agree with the idea of unlimited attempts for DPM but this examination can be organised according to the standards set by the College.

MRCPsych is undoubtedly the most prestigious qualification and even if the DPM examination is started its value would not diminish, so at least some consideration should be given to this idea.

Leicester General Hospital

RAMEEZ ZAFAR

Leicester LE5 4PW

DeAr SirS

Thank you for giving us the opportunity of reading Dr Zafar's letter.

I think that reference to our reply will indicate that we said many overseas trainees, not most will not wish to take MRCPsych seriously. The question of an alternative examination is being considered by the College as we indicated.

With regard to the financial aspects, as Dr Zafar points out, it might well be possible to make a new examination self-financing, but money is not the only matter to be considered. The setting up of any new examination takes other resources, particularly space and personnel, and this has to be considered with respect to the College generally.

Dr Sheila A. ManN

Chief Examiner

Dr Fiona Caldicott

Dean

\section{Requirements for submission of medical articles}

Dear Sirs

The recent correspondence about requirements for submission of medical articles (Psychiatric Bulletin, $1991,15,703$ ) highlights the need for a review of the current system and a widening of the current debate. The prevalence of disputes among authors is unknown. Up to now authors have operated an honour system and are assumed to have discussed alterations and the order of authors. Problems can occur with junior doctors who are under increasing pressure to publish in order to further their careers. It may not always be clear to them what standards apply. Some journals require written permission from all authors before they will publish. Perhaps journals should have a set of guidelines which are sent to the authors on acceptance of an article. These could include confirmation that the order of authorship has been agreed and reflects an appropriate input into the article and that all authors have seen the final draft of the article. The originality and authenticity of the research should also be confirmed. A consensus in guidelines among editors of journals would also help limit confusion.

Research determines a major part of a junior doctor's career progression. This results in pressure to publish which can lead to inadequate and poorly supervised research. The proliferation of medical journals is testament to this. Perhaps appointments committees could also limit the number of papers a candidate could cite.

Wolfson Building

VIVIENNE SCHNIEDEN

Middlesex Hospital

London WIN 8AA

Editorial note. Our Notice to Contributors now states that all material submitted for publication to the Psychiatric Bulletin should be accompanied by a covering letter to the editors signed by all authors.

\section{When relatives refuse to give consent}

DeAr Sirs

With regard to the letter concerning the use of the Mental Health Act 1983 from Jon Kennedy (Psychiatric Bulletin, 1991, 15, 701), I would like to comment 